Review

\title{
Heart rate variability measure in breast cancer patients and survivors: A systematic review
}

\author{
Claudia Arab ${ }^{\mathrm{a}, *}$, Daniel Penteado Martins Dias ${ }^{\mathrm{b}}$, Renata Thaís de Almeida Barbosa ${ }^{\mathrm{c}, 1}$, \\ Tatiana Dias de Carvalho ${ }^{c}$, Vitor Engrácia Valenti ${ }^{\mathrm{d}}$, Tânia Brusque Crocetta ${ }^{\mathrm{c}}$, \\ Marcelo Ferreira ${ }^{\mathrm{c}}$, Luiz Carlos de Abreu ${ }^{\mathrm{c}, \mathrm{e}, 1}$, Celso Ferreira ${ }^{\mathrm{a}}$ \\ a Departamento de Medicina (Cardiologia), Escola Paulista de Medicina, Universidade Federal de São Paulo (UNIFESP), 715 Napoleão De Barros St., São \\ Paulo, SP 04024-002, Brazil \\ ${ }^{\mathrm{b}}$ Departamento de Fisiologia, Faculdade de Medicina de Ribeirão Preto, Universidade de São Paulo (USP), 3900 Bandeirantes Av, Ribeirão Preto, SP \\ 14049-900, Brazil \\ c Departamento de Saúde da Coletividade, Faculdade de Medicina do ABC (FMABC), 821 P Rincipe De Gales Av, Santo Andre, SP 09060-650, Brazil \\ d Centro de Estudos do Sistema Nervoso Autônomo, Departamento de Fonoaudiologia, Faculdade de Filosofia e Ciências, Universidade Estadual Paulista \\ "Júlio de Mesquita Filho" (UNESP), 737 Hygino Muzzi Filho Av, Marília, SP 17525-901, Brazil \\ e Faculdade de Saúde Pública, Universidade de São Paulo (USP), 715 Doutor Arnaldo Av, Sao Paulo, SP 01246-904, Brazil
}

\section{A R T I C L E I N F O}

\section{Article history:}

Received 30 September 2015

Received in revised form 17 February 2016

Accepted 18 February 2016

\section{Keywords:}

Breast neoplasm

Autonomic nervous system

Cardiovascular physiology

Sympathetic nervous system

Parasympathetic nervous system

Cardiac electrophysiology

\begin{abstract}
A B S T R A C T
Purpose: In the current study, we aimed to review literature findings showing the clinical importance of cardiac autonomic modulation assessed by heart rate variability analysis in breast cancer (BC) patients and survivors.

Methods: We conducted a systematic review according to The PRISMA Statement in Medline, Scopus and Web of Science (_-2015) databases. The search was limited to articles in English language, published in peer-reviewed journals, and with adult age samples only (e.g., women, patients, or survivors, diagnosed with BC in any stage). We included observational studies and randomized trials. Detailed heart rate variability analysis (instruments, data collection protocol, and analysis methods) was required. Search terms included autonomic nervous system, heart rate variability, sympathetic and parasympathetic nervous system, autonomic dysfunction, vagal nervous and breast neoplasms, breast cancer and breast tumor. Results: Twelve studies were included in this review. The clinical importance of cardiac autonomic modulation assessed by heart rate variability analysis in BC patients and survivors is demonstrated by association with effects of BC surgery, and treatments, and the adverse effects of surgery and treatments on survivors (e.g., cardiotoxicity, fatigue, and stress).

Limitations: The strength of evidence of included studies is low: small samples size and heterogeneity, presence of confounders, and observational studies design.

Conclusions: The heart rate variability analysis could be used as a complementary non-invasive tool for the early diagnosis and better prognosis of autonomic dysfunction, and survival in BC patients. There are many potential clinical applications of heart rate variability analysis in $\mathrm{BC}$ patients, and the employment of such approaches could lead to lower impairment of autonomic function in this individuals.
\end{abstract}

(C) 2016 Elsevier Ltd. All rights reserved.

\section{Contents}

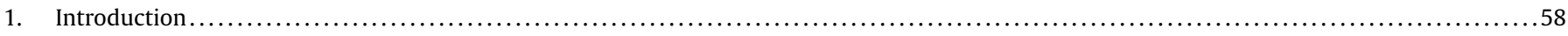

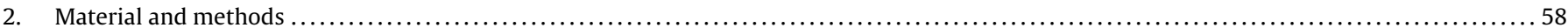

\footnotetext{
* Corresponding author at: 121 Fagundes Varela St., Santo Andre, SP 09060-510, Brazil.

E-mail addresses: ac.arabclaudia@gmail.com (C. Arab), danielpenteado@gmail.com (D.P.M. Dias), profrenatathais@gmail.com (R.T.d.A. Barbosa), carvalho.td1@gmail.com (T.D.d. Carvalho), vitor.valenti@gmail.com (V.E. Valenti), taniabrusque@gmail.com (T.B. Crocetta), doutormarcelof@gmail.com (M. Ferreira), abreu.luizcarlos@gmail.com (L.C.d. Abreu), ferreira-celso@uol.com.br (C. Ferreira).

1 Double name.
} 


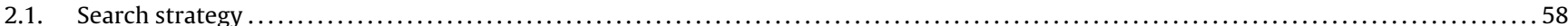

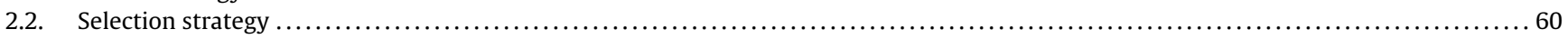

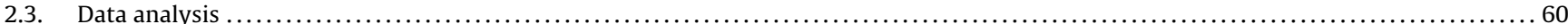

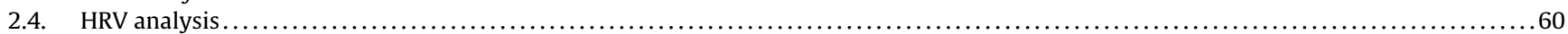

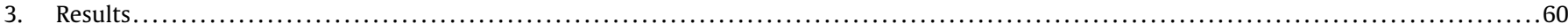

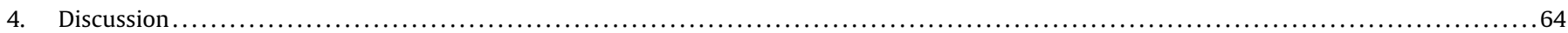

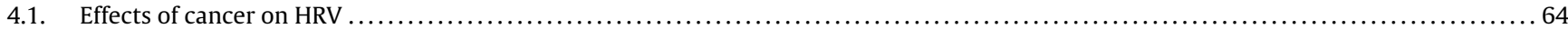

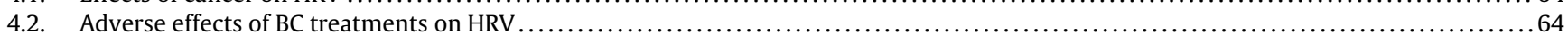

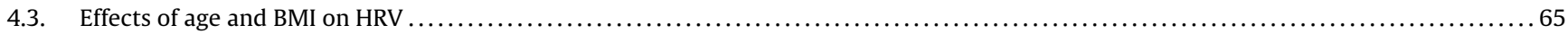

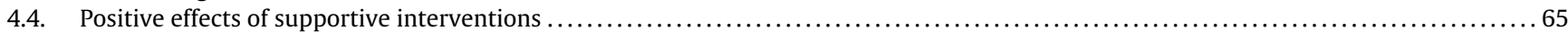

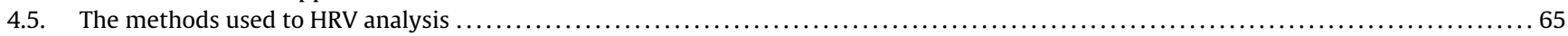

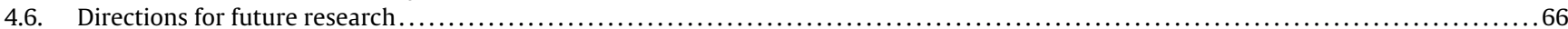

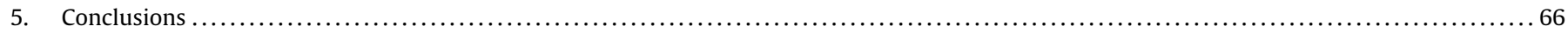

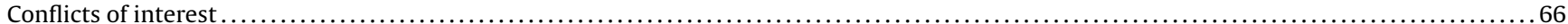

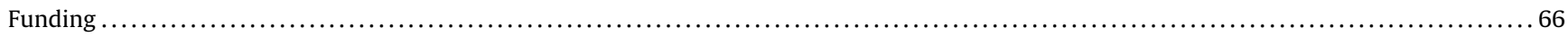

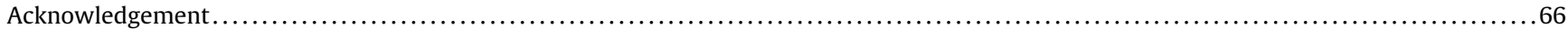

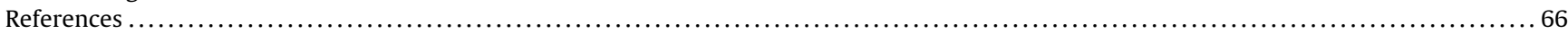

\section{Introduction}

Breast cancer (BC) is the second most common cancer in the world and by far the most frequent cancer among women. There are an estimated 1.67 million new BC cases diagnosed in 2012 (25\% of all cancers), and it ranks as the fifth leading cause of death from cancer overall (522,000 deaths) (Ferlay et al., 2015). Complications of BC therapies are common, e.g., cardiovascular disease, which is fairly frequent and leads to morbidity, poor quality of life, and premature mortality (Scott et al., 2014). Autonomic nervous system (ANS) function is one component involved in the etiology and the clinical course of BC therapy-induced cardiovascular disorders (Scott et al., 2014).

Lakoski et al. (2015) propose the potential mechanisms associated with both autonomic dysfunction and increased cardiovascular disease risk in $\mathrm{BC}$ patients. According to the authors, diagnosis of $\mathrm{BC}$ is associated with therapy-induced cardiovascular injury and lifestyle perturbations, leading to increased activation of the sympathetic nervous system and decreased activation of the parasympathetic nervous system. Successively, this autonomic imbalance stimulates the hypothalamic-pituitary-adrenal axis, the renin-angiotensin-aldosterone system, and the endocannabinoid system, leading to increased oxidative stress, reduced vasodilation, increased inflammation, and atherosclerosis progression (Lakoski et al., 2015).

Evidence in the literature suggests a bi-directional relation between tumoral microenvironment and ANS (Ondicova and Mravec, 2010). The vagus nerve constitutes the main nerve of the parasympathetic nervous system. Physiologically, the vagus nerve has communicative (mediating) and homoeostatic (modulating) roles (De Couck et al., 2012); it also plays a critical role in preventing multiple diseases (Erin et al., 2008). Gidron et al. (2005) propose that the vagus nerve is an important candidate route by which the brain receives information about preclinical visceral tumor signals, modulating partly the tumor development and progression. Erin et al. (2008) demonstrated for the first time inhibition of vagal nervous, increasing systemic metastases of BC cells in mice. In addition, low vagal modulation is taken as a risk factor of diseases and poor prognosis (De Couck et al., 2012), and evidence shows the sympathetic nervous system influences cancer progression and initiation and seems to promote metastasis in solid epithelial tumors (Cole and Sood, 2012). In animal models, stress-induced release of catecholamines can activate beta-adrenergic receptors on tumor cells leading to increased expression of genes, which results in enhanced tumor vascularization and more aggressive growth and spread of malignant cells (Thaker et al., 2006). Barron et al. (2011) showed in human the use of a nonselective $\beta_{1} / \beta_{2}$ - adrenergic receptor antagonist associated with less advanced $\mathrm{BC}$ at diagnosis and lower BC-specific mortality (i.e., 81\% lower for propranolol users than for nonusers). Similarly, Melhem-Bertrandt et al. (2011) results showed BC patients taking beta-blockers had a better 3-year relapse-free survival ( $87 \%$ ) compared with patients not taking beta blockers (77\%).

The vagal and sympathetic activities are in constant interaction (Task Force, 1996). Heart rate variability (HRV) is a nonspecific marker of ANS function and provides a multidimensional measure of ANS through sympathetic and parasympathetic modulation of cardiac function (Karvinen et al., 2013). HRV was the first noninvasive methodology extensively used to evaluate autonomic modulation of the sinus node in normal subjects and in patients with different cardiac and non-cardiac diseases (Lombardi and Stein, 2011). HRV analysis depicts the oscillation in the interval between consecutive heartbeats as well as the oscillations between consecutive instantaneous heart rates (Task Force, 1996).

HRV provides an important index as a potential marker of stress and health for organism functions associated with adaptability and health (Thayer et al., 2012) and as a method to identify patients at risk for an increased cardiac mortality (Lombardi and Stein, 2011). Currently, HRV is considered a predictor of organism functions; low values of HRV are related to cardiovascular risk factors (Vanderlei et al., 2009) and can be an efficient predictor of survival in patients with advanced cancer (Chiang et al., 2013; Wang et al., 2013). BC patients can present lower HRV than healthy people, which implies vagal dysfunction and could be used as a risk factor for cardiovascular diseases (Caro-Morán et al., 2016).

HRV analysis has the potential to provide additional valuable insight into multiple physiological and pathological conditions (Task Force, 1996), and this kind of analysis has been employed in several studies over the past years. In the present study we aimed to investigate the clinical importance of cardiac autonomic modulation assessed by HRV analysis in BC patients and survivors. We expect to find out the possible repercussion of HRV analysis on BC treatment and patients survival.

\section{Material and methods}

We conducted a systematic review according to The Preferred Reporting Items for Systematic Reviews and Meta-Analyses (PRISMA) Statement (Liberati et al., 2009; Moher et al., 2009).

\subsection{Search strategy}

The articles used in the current review were obtained up to December 2015, and the search was limited to articles in English 

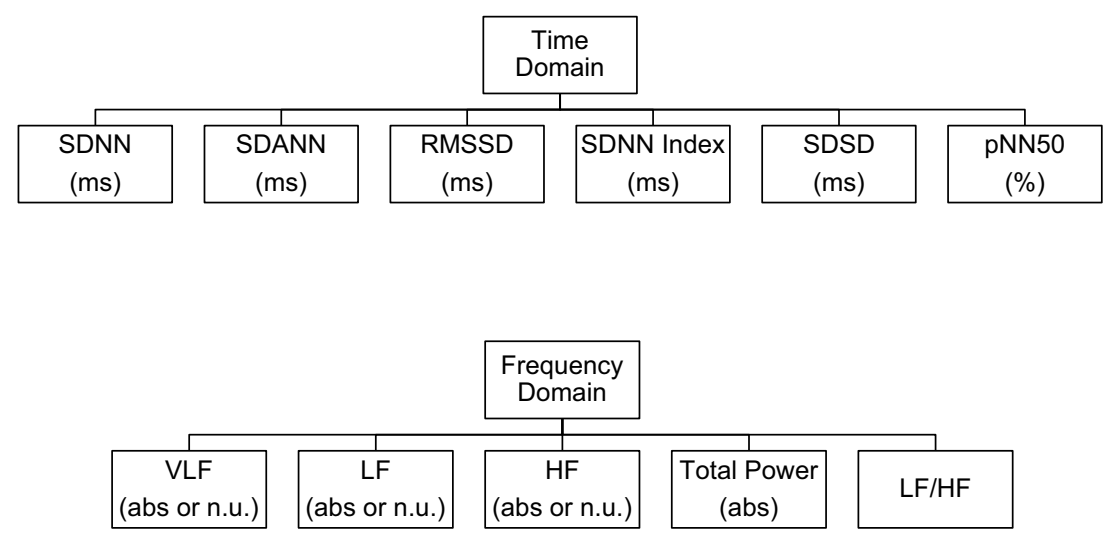

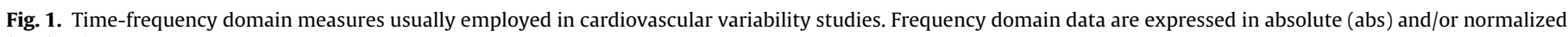
(n.u.) units.

language, published in peer-reviewed journals, and with adult age samples only. The participants of the studies should be women, patients, or survivors, diagnosed with BC in any stage. Studies with women with other types of cancer, secondary cancer, and studies with adult men were not considered for the current study. This review included observational studies and randomized trials, investigating clinical and/or general population samples, and using a wide variety of quantitative methodological approaches. The type of interventions of included studies must have focused on HRV evaluation in $B C$ patients or survivors related to subjects and/or disease features. We excluded review, meta-analysis and pilot studies and other types of paper (e.g., author manuscript, letters to editors).

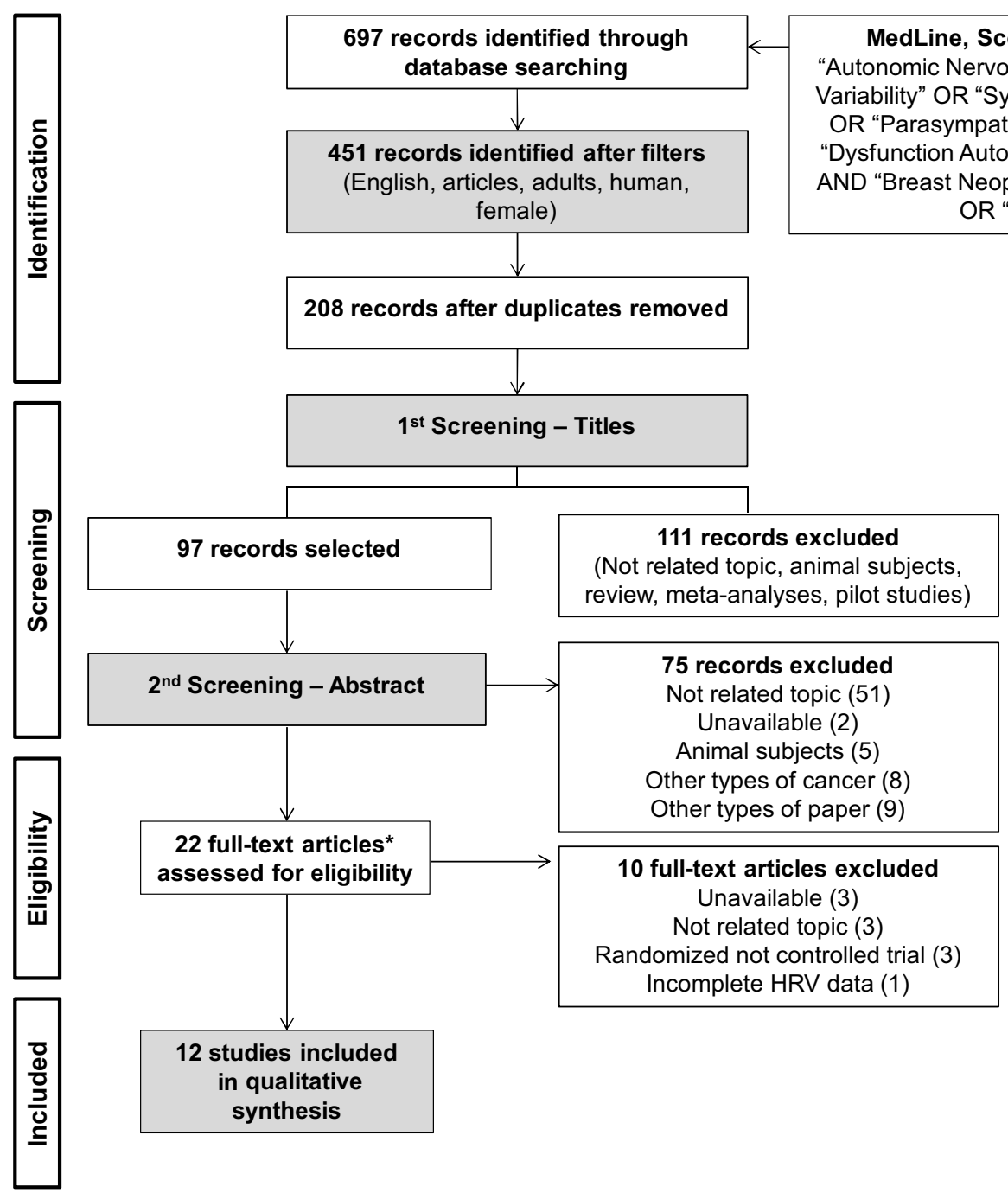

*763 references of the analyzed full-text articles 25 records selected by title: Duplicates (16)

Other types of cancer (2) Not related topic (7)

Fig. 2. Literature review citation selection flowchart (adapted from Moher et al., 2009). 
A systematic literature search of studies without limits on the publication dates was undertaken on the computerized medical databases Medline (via PubMed, http://www.pubmed. com), Scopus (http://www.scopus.com), and Web of Science (https://isiknowledge.com). The following search terms were used: "Autonomic Nervous System" OR "Heart Rate Variability" OR "Sympathetic Nervous System" OR "Parasympathetic Nervous System" OR “Autonomic Dysfunction" OR "Vagal Nervous" AND "Breast Neoplasms" OR "Breast Cancer" OR "Breast Tumor" in the titles and/or in the abstracts. The limiters were as follows: Scholarly (peerreviewed) journals, English Language, Human, Adult (> 18years), and Female. The keywords were selected according to the Medical Subject Headings (MeSH) in the National Library of Medicine and also by their synonyms.

\subsection{Selection strategy}

Initially, we undertook a screening of titles related to the topic. This selection was based on evidence that related cardiac autonomic control (via HRV) with BC. At the end of this stage, we excluded duplications. Secondly, we conducted a detailed reading of the abstracts of the selected articles, according to those that addressed only the behavior of the autonomic nervous system via some protocol in patients with BC. We excluded abstracts not related to the issue. Respiratory sinus arrhythmia occurrence was taken as exclusion criteria. The full texts then were evaluated, and those that did not fit the exclusion criteria were included in the current review. A search also was conducted in the references of the full texts.

To increase confidence in the selection of articles, all search and selection stages were reviewed independently by two researchers who, after reading all of the potential articles, reached a consensus to establish which articles fit the inclusion criteria (Liberati et al., 2009).

\subsection{Data analysis}

After study selection, criteria were followed to maintain the evaluation of the studies within narrow standards. The first and essential criterion was that all details regarding HRV analysis should be verified, with a description of instruments, data collection protocol, and HRV analysis methods (Subsection 2.4)

Next, the articles were evaluated according to subjects, ethical considerations (committee ethic approval and informed written consent), and detailed data collection procedures. At least two out of the four following items were required to consider the study for the current review: (a) inclusion and exclusion factors, (b) comparison between groups, (c) sample loss, and (d) sample size. Concerning the randomized trials, only controlled trials were considered.

Finally, we followed the Grades of Recommendation, Assessment, Development, and Evaluation (GRADE) Working Group (GRADE Working Group, 2004) to grant strength of evidence to the included studies. The main element considered in strength of evidence was study design, broadly categorized as observational studies (low evidence) and randomized trials (high evidence). Study quality (detailed study methods and execution) and presence of several limitations secondarily were considered in strength of evidence analysis.

\subsection{HRV analysis}

The analysis of cardiovascular variability can be carried out by means of several approaches. The linear methods commonly used in both clinical and experimental settings can categorize in bundles; for the scope of this review, time domain measures and frequency domain measures were considered (Zaza and Lombardi, 2001). In brief, all methods initially rely on proper data acquisition and processing, including the choice of appropriate sampling rate (Durosier et al., 2014; Ellis et al., 2015; Hejjel and Roth, 2004) and employment of efficient algorithms capable of detecting cardiac cycles in electrocardiogram (ECG) and/or pulsatile arterial pressure tracings (Mollakazemi et al., 2015).

Following detection of individual cardiac cycles, the computer programs usually generate a beat-by-beat time series with all cardiovascular parameters values along with time values. Time series then are processed, and several parameters are calculated. Regarding the most common time domain measures (Task Force, 1996), we can highlight: SDNN (ms), the standard deviation of all normal-tonormal cardiac intervals; SDANN ( $\mathrm{ms}$ ), the standard deviation of the means of normal-to-normal heart periods obtained from all 5-min periods throughout the whole data series; RMSSD (ms), the square root of the mean of the sum of the squares of differences between adjacent normal-to-normal cardiac intervals; SDNN index ( $\mathrm{ms}$ ), the average of the standard deviations of all normal-to-normal intervals calculated from all 5 -min periods of the whole recording; SDSD ( $\mathrm{ms}$ ), the standard deviation of differences between contiguous normal-to-normal intervals; and, pNN50 (\%), the percentage of adjacent normal-to-normal intervals differing more than $50 \mathrm{~ms}$ throughout the whole recording (see Fig. 1).

Beat-to-beat time series also can be analyzed by means of frequency domain methods, which have the advantage of providing both frequency and amplitude information with regard to oscillations in cardiovascular parameters (Shaffer et al., 2014). There are reports in the literature showing that the Fast Fourier Transform (FFT) is a useful approach for cardiovascular variability analysis (Badilini et al., 1998; Cerutti et al., 1991; Højgaard et al., 1998), as it is capable of processing time series and calculating a spectrum in which individual frequency bands can analyzed. Briefly, the values are expressed as the power spectral density (PSD) calculated from the whole spectrum(i.e., total power) or from frequency bands three spectral components are distinguished: very low frequency (VLF), low frequency (LF), and high frequency (HF) (Shaffer et al., 2014; Task Force, 1996). Concerning the usual frequency domain parameters calculated from the spectrum aiming the analysis of HRV, we should highlight the power of the VLF, LF, and HF bands in absolute (e.g., bpm ${ }^{2}$ or $\mathrm{ms}^{2}$ ) and/or normalized (i.e., n.u.) units; the ratio between LF and HF power, both in absolute units (e.g., bpm ${ }^{2}$ or $\mathrm{ms}^{2}$ ); and, the total power of the whole spectrum (e.g., bpm ${ }^{2}$ or $\mathrm{ms}^{2}$ ) (Task Force, 1996) (see Fig. 1).

Considering the analysis of HRV as a valuable tool for assessing the autonomic modulation of cardiac rhythmicity, the power of the LF band of the heart period spectrum is taken as an index of cardiac sympathetic modulation (Malliani et al., 1991; Rimoldi et al., 1990) or as an index of both sympathetic and parasympathic modulation (Appel et al., 1989). On the other hand, the respiratory rhythm of heart period variability, expressed as HF oscillations, is taken as an index of vagal modulation over the heart (Malliani et al., 1997, 1991; Pomeranz et al., 1985). Experimental approaches like electrical stimulation of the vagus nerve, muscarinic receptor blockade, and vagotomy support the concept of vagal activity as the main contributor to HF oscillations (Akselrod et al., 1981; Malliani et al., 1991; Pomeranz et al., 1985).

\section{Results}

A total of 451 records were screened after data were filtered and duplicates removed. Twelve studies were included in this review (see Fig. 2): 2 randomized controlled trials (Meinardi et al., 2001; Minowa and Koitabashi, 2013), 1 randomized singleblind placebo-controlled crossover (Fernández-Lao et al., 2012); 
and 9 observational studies (Bettermann et al., 2001; CantareroVillanueva et al., 2012; Crosswell et al., 2014; Fagundes et al., 2011; Giese-Davis et al., 2015, 2006; Hansen et al., 2013; Tjeerdsma et al. 1999; Vigo et al., 2015).

Data are presented in Table 1 with a description of the studies according to theme related to HRV, population, investigation parameters, clinical findings, and potential values.

The studies included in this research were performed in patients undergoing BC treatment, surgery (Hansen et al., 2013; Minowa and Koitabashi, 2013), and chemotherapy (CT) (Meinardi et al., 2001; Tjeerdsma et al., 1999), and in BC survivors (Bettermann et al., 2001; Cantarero-Villanueva et al., 2012; Crosswell et al., 2014; Fagundes et al., 2011; Fernández-Lao et al., 2012; Giese-Davis et al., 2015, 2006; Vigo et al., 2015).

Seven studies investigated patients diagnosed with earlyto intermediate-stage BC (Cantarero-Villanueva et al., 2012; Crosswell et al., 2014; Fagundes et al., 2011; Fernández-Lao et al., 2012; Hansen et al., 2013; Meinardi et al., 2001; Vigo et al., 2015), and 3 studies included metastatic BC patients (Giese-Davis et al., 2015, 2006; Tjeerdsma et al., 1999). Finally, 2 studies included patients with diagnosis of BC in any stage (Bettermann et al., 2001; Minowa and Koitabashi, 2013).

The purposes of these studies were to investigate HRV in BC patients as a measure of cardiac autonomic function and its correlation with adverse effects of the disease, surgery and/or treatments. The main topics were cardiotoxicity induced by chemotherapy (Tjeerdsma et al., 1999; Meinardi et al., 2001), response to stress (Giese-Davis et al., 2006), association with fatigue (Crosswell et al., 2014; Fagundes et al., 2011; Fernández-Lao et al., 2012), depression status (Giese-Davis et al., 2006), and survival rate (Giese-Davis et al., 2015).

The research of Bettermann et al. (2001) was the first study comparing the autonomic regulatory dysfunction in BC and other diseases (e.g., diabetes mellitus). As compared to healthy and diabetic subjects, no difference was seen in BC patients (i.e., $56 \pm 12$ years old, 30\% metastasized) who had no radiation or CT for at least 3 months and no operation for at least 1 week before data sampling for HRV analysis (Bettermann et al., 2001).

Two studies used HRV measures associated to effects of BC surgery. Hansen et al. (2013) investigated HRV as circadian variation, and Minowa and Koitabashi (2013) examined it as a measure of relaxation level. Hansen et al. (2013) confirmed severe disturbances of the ANS, measured through HRV analysis, after BC surgery-lumpectomy. The disturbances consisted of a lack of circadian variations and a lower cardiac parasympathetic modulation postoperatively, that had not been fully normalized even 14 days after surgery. The circadian variation was before surgery for pNN50 and RMSSD with higher values during the night than in the evening, but this variation was missing one and 14 days after surgery. The modified modulation was: decreased SDNN and pNN50 from preoperative to one and 14 days postoperative; SDNN increased again from one to 14 days postoperative; and RMSSD decreased from pre to one day postoperative. The authors suggested alternative treatments could be important because of the occurrence of postoperative complications associated with decreased HRV. Also, in a risk population undergoing surgery, shifts in autonomic balance towards sympathetic predominance therefore might result in increased risk of cardiovascular morbidity (Hansen et al., 2013).

Minowa and Koitabashi (2013) hypothesized that the stress of surgery could be softened if patients started to relax during the perioperative period, helping in terms of stress management. Thus, they investigated the impact of auto-relaxation techniques on perioperative anxiety and pain in patients with $\mathrm{BC}$. The protocol consisted of 20 min of relaxation music and verbal formulae 3 times a day within 3 days following surgery. The cardiac parasympathetic modulation (i.e., HF) was found to be higher in the relaxation group and increased in the postoperative moments (1-3 days following surgery). No differences were reported in LF/HF ratios. In this context, the practice of the relaxation protocol caused higher cardiac parasympathetic modulation and greater relaxation (Minowa and Koitabashi, 2013).

To analyze cardiotoxicity effects of CT, Tjeerdsma et al. (1999) investigated patients with locally advanced or metastatic BC who had been treated with anthracyclines compared to healthy group. HRV was found reduced in advanced BC patients (45 years old) after treatment with anthracyclines, as compared to control subjects. Both the frequency (i.e., LF, HF, and TP) and time (pNN50 and RMSSD) domain measures were lower in BC patients when compared to healthy subjects. The SDANN and SDNN parameters were found to be similar between BC patients and healthy controls. The authors observed normal autonomic function in $15 \%$ of the patients, and $85 \%$ had abnormal HRV parameters in the frequency and time domains, but the authors did not describe the classification of normal or abnormal autonomic function. In addition, HRV measures were not affected by the doses of CT and by the side of the chest in which the irradiation was applied. Finally, it was suggested that HRV measures could be taken as a precise tool for the early detection of anthracycline-induced cardiac damage (Tjeerdsma et al., 1999).

Meinardi et al. (2001) also observed no persistent reduction of HRV after anthracycline CT in BC patients. In a higher-dose CT group, several HRV parameters (SDNN, SDANN, RMSSD, square root of LF, HF, and TP) were reduced in a more pronounced fashion at 1 month after CT as compared to the beginning of treatment. On the other hand, parameters returned to their baseline values at 1 month after the completion of the radiotherapy and at 1 year after the start of CT. The impairment of cardiac function was most clearly indicated by a decline in the mean left ventricular ejection fraction as a result of myocardial damage, independent of the CT doses received (Meinardi et al., 2001).

The major part of included studies focused on ANS associated with side effects of BC treatment and concern in BC survivors about factors such as fatigue (Crosswell et al., 2014; Fagundes et al., 2011; Fernández-Lao et al., 2012), depression and stress response (GieseDavis et al., 2006), reduced physical function (Cantarero-Villanueva et al., 2012), and survival (Giese-Davis et al., 2015). Vigo et al. (2015) hypothesized that in $\mathrm{BC}$ survivors multiple functional alterations might define a phenotype, which includes vagal impairment.

Fagundes et al. (2011) evaluated relationships between fatigue and both sympathetic and parasympathetic nervous system activity in BC survivors. The researchers subjected BC survivors to a standardized stressor. The results showed that women who reported more fatigue also had significantly lower cardiac vagal modulation, measured by HRV (RMSSD and HF), before and after the stressor. The association between HRV and fatigue was not mediated by treatment type, cancer stage, and time since treatment (Fagundes et al., 2011).

In the Crosswell et al. (2014) study, HRV analysis (RMSSD and $\mathrm{HF}$ ) was employed to assess the cardiac parasympathetic modulation in younger BC survivors. The researchers observed BC patients with lower HRV (low RMSSD) reporting higher fatigue. HRV parameters were significantly negatively correlated with inflammation (interleukin-6 and C-reactive protein), but these correlations were attenuated after controlling age and BMI,. There was no association between HRV and treatment variables (i.e., CT, radiation, or endocrine therapy) and the type of surgery (i.e., lumpectomy or mastectomy). Nevertheless, the association between HRV and fatigue was not mediated by inflammation; instead, associations between HRV and fatigue appeared to be driven by age and body mass index (BMI). These findings identify parasympathetic drive as a potential contributor to fatigue experienced in the post-treatment period (Crosswell et al., 2014). 
Table 1

Summary of selected studies investigating the clinical importance of cardiac autonomic modulation assessed by HRV analysis in BC patients and survivors.

\begin{tabular}{|c|c|c|c|c|c|}
\hline Theme & Selected articles & $\begin{array}{l}\text { Population (\# } \\
\text { participants) }\end{array}$ & $\begin{array}{l}\text { Investigation parameter } \\
\text { (statistical analysis) } \\
\text { instrument }\end{array}$ & Clinical findings & Potential value \\
\hline Disease Comparison & $\begin{array}{l}\text { Bettermann et al. } \\
\text { (2001) }\end{array}$ & $\begin{array}{l}52 \text { BC patients, } 53 \\
\text { women with diabetes } \\
\text { mellitus, } 53 \text { healthy } \\
\text { women (age-matched) }\end{array}$ & $\begin{array}{l}\text { Spectral FFT [(LF, HF, LF/HF } \\
\text { ratio (ms)-not } \\
\text { log-transformed] } \\
\text { (non-parametric) } 24 \mathrm{~h} \\
\text { Holter }^{\mathrm{b}}\end{array}$ & $\begin{array}{l}\leftrightarrow \text { HRV cancer, diabetic } \\
\text { and healthy groups } \\
\leftrightarrow \text { HRV metastatic than } \\
\text { non-metastatic BC }\end{array}$ & $\begin{array}{l}\text { HRV was not } \\
\text { determined during } \\
\text { controlled conditions, } \\
\text { many factors might } \\
\text { have interfered HRV }\end{array}$ \\
\hline \multirow[t]{2}{*}{ Effects of BC Surgery } & Hansen et al. (2013) & $\begin{array}{l}12 \text { BC patients } \\
\text { scheduled for } \\
\text { lumpectomy }\end{array}$ & $\begin{array}{l}\text { Time domain [SDNN, } \\
\text { RMSSD (ms), pNN50 (\%)] } \\
\text { (non-parametric) } 24 \mathrm{~h} \\
\text { Holter }^{\mathrm{f}}\end{array}$ & $\downarrow$ HRV post-operative & $\begin{array}{l}\text { There are severe } \\
\text { disturbances of the } \\
\text { ANS (lower } \\
\text { parasympathetic tone) } \\
\text { after lumpectomy, } \\
\text { which has not been } \\
\text { fully normalized } \\
14 \text { days after surgery }\end{array}$ \\
\hline & $\begin{array}{l}\text { Minowa and } \\
\text { Koitabashi (2013) }\end{array}$ & $\begin{array}{l}60 \text { patients diagnosed } \\
\text { with } B C \text { and scheduled } \\
\text { for surgery }\end{array}$ & $\begin{array}{l}\text { Frequency domain [HF } \\
\left(\mathrm{ms}^{2}\right), \mathrm{LF} / \mathrm{HF} \text { ratio] } \\
\text { (parametric assumption) } \\
\text { ECG }^{\mathrm{e}}\end{array}$ & $\begin{array}{l}\uparrow \text { HRV group relaxation } \\
\leftrightarrow \text { HRV group control }\end{array}$ & $\begin{array}{l}\text { The practice of the } \\
\text { relaxation protocol } \\
\text { caused higher } \\
\text { parasympathetic } \\
\text { nervous system } \\
\text { activity and greater } \\
\text { relaxation in BC } \\
\text { patients on } \\
\text { postoperative }\end{array}$ \\
\hline \multirow[t]{2}{*}{$\begin{array}{l}\text { Cardiotoxicity effects } \\
\text { of } C T\end{array}$} & Meinardi et al. (2001) & $\begin{array}{l}40 \mathrm{BC} \text { patients after } \\
\text { mastectomy or } \\
\text { breast-conserving } \\
\text { treatment }\end{array}$ & $\begin{array}{l}\text { Time domain [SDNN, } \\
\text { SDANN, RMSSD (ms)] and } \\
\text { Spectral FFT [LF, HF, TP } \\
\text { (ms)- square root] } 24 \mathrm{~h} \\
\text { Holter }^{\mathrm{d}}\end{array}$ & $\begin{array}{l}\leftrightarrow \text { HRV low-dose CT } \\
\downarrow \text { HRV high-dose CT one } \\
\text { month after CT HRV } \\
\text { returned to baseline } \\
\text { values at one month } \\
\text { after RT and one year } \\
\text { after CT }\end{array}$ & $\begin{array}{l}\text { No persistent reduction } \\
\text { of HRV was observed } \\
\text { after anthracycline CT } \\
\text { in BC patients }\end{array}$ \\
\hline & Tjeerdsma et al. (1999) & $\begin{array}{l}20 \text { patients with locally } \\
\text { advanced or metastatic } \\
\text { BC } \\
20 \text { age-matched } \\
\text { healthy controls }\end{array}$ & $\begin{array}{l}\text { Time [SDNN, SDANN, } \\
\text { RMSSD (ms), pNN50 (\%)] } \\
\text { and frequency [LF, HF, TP } \\
\text { (ms)] domain } \\
\text { (non-parametric) } 24 \mathrm{~h} \\
\text { Holter }^{\mathrm{d}}\end{array}$ & $\begin{array}{l}\downarrow \text { HRV BC patients } \\
\text { CT Doses and side of } \\
\text { irradiation of the chest } \\
\text { wall did not present } \\
\text { difference in HRV }\end{array}$ & $\begin{array}{l}\text { Asymptomatic BC } \\
\text { patients with normal } \\
\text { LVEF, treated with high } \\
\text { dose anthracycline } \\
\text { based CT and RT, have } \\
\text { a high prevalence of } \\
\text { autonomic impairment }\end{array}$ \\
\hline \multirow[t]{5}{*}{$\begin{array}{l}\text { Adverse effects in BC } \\
\text { survivors }\end{array}$} & $\begin{array}{l}\text { Cantarero-Villanueva } \\
\text { et al. (2012) }\end{array}$ & $\begin{array}{l}95 \text { BC survivors ( } 6 \\
\text { months max. post } \\
\text { initial therapy) }\end{array}$ & $\begin{array}{l}\text { Time [SDNN, RMSSD, (ms), } \\
\text { HRV index] and frequency } \\
{\left[\mathrm{LF}, \mathrm{HF}, \mathrm{TP}\left(\mathrm{ms}^{2}\right), \mathrm{LF} / \mathrm{HF}\right.} \\
\text { ratio] domain } \\
\text { (non-parametric) } 5 \mathrm{~min} \\
\text { rest supine, ECG }\end{array}$ & $\begin{array}{l}\text { HRV and handgrip } \\
\text { strength was weakly } \\
\text { associated }\end{array}$ & $\begin{array}{l}\text { The relation between } \\
\text { HRV and handgrip } \\
\text { strength may help to } \\
\text { better understand the } \\
\text { recovery processes } \\
\text { after exercise }\end{array}$ \\
\hline & Crosswell et al. (2014) & $\begin{array}{l}84 \text { women originally } \\
\text { diagnosed with early } \\
\text { stage BC prior to age } 50\end{array}$ & $\begin{array}{l}\text { Time }[\text { RMSSD }(\mathrm{ms})] \text { and } \\
\text { frequency }\left[\mathrm{HF}\left(\mathrm{ms}^{2}\right)-\log \right. \\
\text { transformed] domain } 15 \\
\text { min rest, ECG }\end{array}$ & $\begin{array}{l}\downarrow \text { HRV older and } \uparrow \text { BMI } \\
\leftrightarrow \text { Demographic, } \\
\text { treatment and physical } \\
\text { activity } \\
\downarrow \text { HRV } \uparrow \text { fatigue }\end{array}$ & $\begin{array}{l}\text { HRV is a potential } \\
\text { contributor to fatigue } \\
\text { experienced in the } \\
\text { aftermath of cancer } \\
\text { treatment }\end{array}$ \\
\hline & Fagundes et al. (2011) & $\begin{array}{l}109 \text { women who had } \\
\text { completed treatment } \\
\text { for early BC within past } \\
2 \text { years, at least } 2 \\
\text { months }\end{array}$ & $\begin{array}{l}\text { Time }[\text { RMSSD }(\mathrm{ms})] \text { and } \\
\text { frequency }\left[\mathrm{HF}\left(\mathrm{ms}^{2}\right)-\log \right. \\
\text { transformed] domain } \\
10 \text { min rest, heart rate } \\
\text { monitor }^{c}\end{array}$ & $\begin{array}{l}\downarrow \text { HRV fatigued patients } \\
\text { pre and post stressor } \\
\text { test }\end{array}$ & $\begin{array}{l}20 \text {-year difference } \\
\text { between fatigued and } \\
\text { non-fatigued BC } \\
\text { survivors. Fatigue may } \\
\text { signify accelerated } \\
\text { aging. } \downarrow \text { HRV have been } \\
\text { associated with } \\
\text { adverse health } \\
\text { outcomes }\end{array}$ \\
\hline & $\begin{array}{l}\text { Fernández-Lao et al. } \\
\text { (2012) }\end{array}$ & $\begin{array}{l}20 \mathrm{BC} \text { survivors } \\
\text { reporting moderate to } \\
\text { high cancer-related } \\
\text { fatigue }\end{array}$ & $\begin{array}{l}\text { Time domain [SDNN, } \\
\text { RMSSD (ms), HRV index] } \\
\text { and Spectral FFT [LF, HF } \\
\left(\mathrm{ms}^{2}\right), \mathrm{LF} / \mathrm{HF} \text { ratio] } \\
\text { (parametric assumption) } \\
5 \text { min rest supine } \\
\text { pre-posttest, ECG }\end{array}$ & $\begin{array}{l}\uparrow \mathrm{HRV} \text { massage group } \\
\leftrightarrow \mathrm{HRV} \text { control group }\end{array}$ & $\begin{array}{l}\text { Massage therapy as a } \\
\text { body-centered early } \\
\text { intervention in } \\
\text { fatigued } B C \text { survivors } \\
\text { reduce fatigue and } \\
\text { improve cardiovascular } \\
\text { autonomic balance }\end{array}$ \\
\hline & $\begin{array}{l}\text { Giese-Davis et al. } \\
(2015)\end{array}$ & $\begin{array}{l}87 \text { patients with } \\
\text { metastatic or } \\
\text { recurrence BC }\end{array}$ & $\begin{array}{l}\text { Spectral FFT }\left[\mathrm{HF}\left(\mathrm{ms}^{2}\right)-\log \right. \\
\text { transformed] } \\
5 \text { min rest, ECG } \\
\text { Median follow up of } 7.99 \\
\text { years }\end{array}$ & $\begin{array}{l}\uparrow \text { baseline HF-HRV } \\
\text { predicted } \uparrow \text { survival }\end{array}$ & $\begin{array}{l}\text { Low HF-HRV as a risk } \\
\text { factor for shorter } \\
\text { survival in women } \\
\text { with a diagnosis of } \\
\text { metastatic or } \\
\text { recurrence BC }\end{array}$ \\
\hline
\end{tabular}


Table 1 (Continued)

\begin{tabular}{|c|c|c|c|c|c|}
\hline Theme & Selected articles & $\begin{array}{l}\text { Population (\# } \\
\text { participants) }\end{array}$ & $\begin{array}{l}\text { Investigation parameter } \\
\text { (statistical analysis) } \\
\text { instrument }\end{array}$ & Clinical findings & Potential value \\
\hline & $\begin{array}{l}\text { Giese-Davis et al. } \\
(2006)\end{array}$ & $\begin{array}{l}45 \text { non-depressed and } \\
45 \text { depressed patients } \\
\text { with metastatic BC }\end{array}$ & $\begin{array}{l}\text { Spectral FFT [HF, } \mathrm{LF}, \mathrm{VLF} \\
\left(\mathrm{ms}^{2}\right) \text {-log transformed] } \\
5 \text { min rest pre-post stressor } \\
\text { test, } \text { ECG }^{\mathrm{b}}\end{array}$ & $\begin{array}{l}\downarrow \text { HRV depressed than } \\
\text { non-depressed } \\
\text { patients pre-test } \\
\downarrow \text { HRV depressed } \\
\text { patients in post-test }\end{array}$ & $\begin{array}{l}\text { Depression was } \\
\text { associated with } \\
\text { alteration in autonomic } \\
\text { regulation at baseline } \\
\text { and during the stressor }\end{array}$ \\
\hline & Vigo et al. (2015) & $\begin{array}{l}171 \text { sedentary } \\
\text { asymptomatic women } \\
\text { (106 } \mathrm{BC} \text { survivors, } 65 \\
\text { controls) of similar age }\end{array}$ & $\begin{array}{l}\text { Spectral powers [LF, HF, } \\
\left.\text { LF/HF ratio }\left(\mathrm{ms}^{2}, \mathrm{nu}\right)\right] \\
\text { (non-parametric) } 7 \mathrm{~min} \\
\text { rest supine, } \mathrm{ECG}^{\mathrm{ns}}\end{array}$ & $\begin{array}{l}\downarrow \text { HRV BC patients } \\
\text { HRV and fatigue } \\
\text { correlated }\end{array}$ & $\begin{array}{l}\text { ANS disturbances as } \\
\text { the primary elements } \\
\text { of a chain of events } \\
\text { eventually linked to } \\
\text { fatigue }\end{array}$ \\
\hline
\end{tabular}

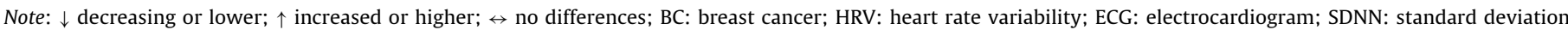

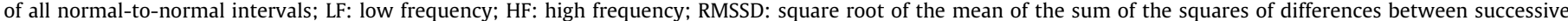

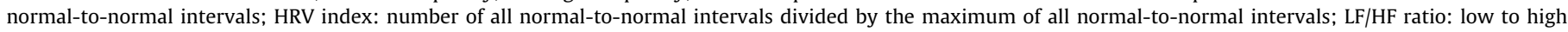

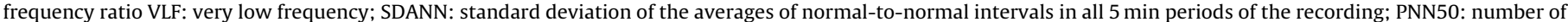

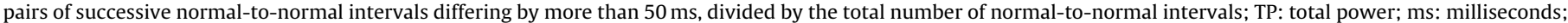

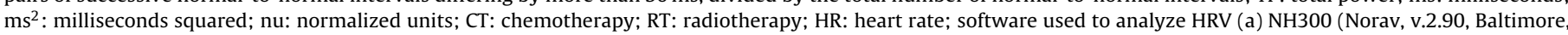

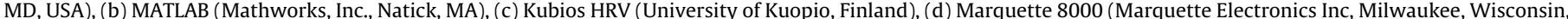

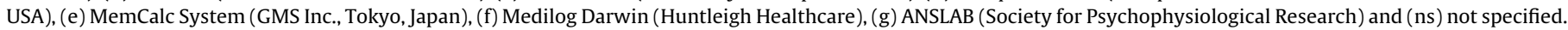

Fernández-Lao et al. (2012) used a randomized single-blind placebo-controlled crossover design to compare the immediate effects of a myofascial release with a control intervention in $\mathrm{BC}$ survivors with cancer-related fatigue. The myofascial intervention consisted of a protocol focused on the neck-shoulder area of approximately $40 \mathrm{~min}$ and included longitudinal stroke, J stroke, sub- occipital sustained pressure, frontalis bone spread, and ear pull techniques. They found increased SDNN, RMSSD, and HF after intervention in $\mathrm{BC}$ survivors with high levels of fatigue. There was a positive correlation between changes in disturbance of mood and SDNN, with greater reduction in the disturbance of mood correlated with a greater increase in SDNN. They suggested the use of massage therapy as a body-centered early intervention in BC survivors to reduce fatigue and to improve cardiovascular autonomic balance (Fernández-Lao et al., 2012).

Giese-Davis et al. (2006) investigated how depression affects metastatic BC stress reactivity, including autonomic and hypothalamic-pituitary-adrenal axis function. This study compared depressed and non-depressed metastatic BC survivors subjected to a standardized and cognitive stressor. The characteristics of study participants were presented in a general way, and most had received treatment with surgery, CT, radiotherapy, and/or hormone therapy. Depression in these patients was associated with alteration in autonomic regulation at the baseline and during the standardized cognitive stressor test. Results suggest a strong effect of depression on vagal attenuation in metastatic BC survivors (Giese-Davis et al., 2006).

Cantarero-Villanueva et al. (2012) related a weak relationship between handgrip strength and ANS function in BC survivors. There was no correlation among handgrip strength and SDNN, RMSSD, HRV index, TP, LF, and LF/HF ratio parameters. The results were the opposite of their hypothesis, which was supported by the following findings: (a) an increase in myofibrillar protein degradation induced by tumor factors and cytokines involved in cancer biology (Al-Majid and McCarthy, 2001) could be associated with a loss of muscular strength in cancer survivors; (b) BC survivors exhibited reduction in muscle strength associated with cancer-related symptoms (Cantarero-Villanueva et al., 2011; Winters-Stone et al., 2008); and (c) reduced physical function was associated with ANS imbalance, as reflected by reduced HRV in patients with cancer (Lin and Chen, 2010).

Giese-Davis et al. (2015) hypothesized that higher initial HFHRVwould be associated with longer survival. A total of 87 patients with metastatic or recurrence BC participated of the study. Fifty patients died during a median follow-up of 7.99 years. At 37.09 months, $50 \%$ of the lower HF-HRV group versus $34.88 \%$ of the women with higher HF-HRV have died. The hypothesis was confirmed and sleep efficiency, visceral metastases, reconstructive surgery, and higher heart rate were significantly correlated to both HF-HRV and predictive survival. No other variables (i.e., disease stage, type of treatment, disease-free interval, estrogen receptor status, physical activity, depression, stress, fatigue, education level and income) met the proxy criteria. For the first time, higher resting HF-HRV significantly predicted longer overall survival, establishing HF-HRV as a long-term predictor of cancer survival. This study suggests the relationship of HF-HRV with survival indicates that efferent cardiac vagal activity may represent overall afferent and efferent information transfers between the vagal and immune systems and may provide early clinical prognoses in cancer patients (Giese-Davis et al., 2015).

Finally, Vigo et al. (2015) investigated the clinical phenotype of BC survivors. Autonomic impairments (reduced aerobic fitness, altered metabolic proxies, and feelings of fatigue) were reported representing the hallmark of the clinical phenotype of BC survivors. HRV analysis revealed BC survivors presenting a lower total RR variance and lower absolute power (in $\mathrm{ms}^{2}$ ) of LF and HF components of HRV. In normalized power, LF and HF were similar in BC survivors and healthy age-matched controls. Multiple HRV indices were correlated to perceived fatigue, and stress and somatic symptoms appeared less tightly correlated. HRV was not different between $\mathrm{BC}$ subgroups (time from surgery, type of surgery, $\mathrm{VO}_{2}$ peak, presence or absence of cardiovascular medications). The results suggest ANS disturbances as the primary elements of a chain of events eventually linked to fatigue (Vigo et al., 2015).

The reviewed studies present risk of bias mostly because of samples, small size and heterogeneity, and presence of confounders. The heterogeneous samples included patients with different characteristics such as the time interval from BC diagnosis (Fernández-Lao et al., 2012), CT regiment (Tjeerdsma et al., 1999), types of surgery (Minowa and Koitabashi, 2013), and diagnosis of autonomic neuropathy, medication, and time interval from major surgery (Bettermann et al., 2001).

The possible confounders presented in studies were BC staging and grading (Bettermann et al., 2001), type of treatment (Cantarero-Villanueva et al., 2012), psychological factors (Bettermann et al., 2001; Hansen et al., 2013; Meinardi et al., 2001), and use of medicaments (Crosswell et al., 2014; Giese-Davis et al., 2006). Most of studies were observational, which can make it dif- 
ficult to establish the cause and effect relationship of the observed associations. Moreover, some of the observed differences could already be present before BC treatment (Vigo et al., 2015).

\section{Discussion}

According to the reviewed studies, the clinical importance of cardiac autonomic modulation assessed by HRV analysis in BC patients and survivors is demonstrated by association with effects of BC surgery, BC treatments, and survival and the adverse effects of surgery and treatments on survivors. HRV seems to be related to common effects due to BC (e.g., fatigue, depression, stress). In clinical practice, assessment of HRV could help in attenuation of $\mathrm{BC}$ adverse effects, and studies have showed association of higher HRV parameters and prolonged survival in cancer patients (Fadul et al., 2010; Kim et al., 2010). The strength of evidence of included studies is low. Because of the observational studies design of most of the included research, it is not possible to establish the causeeffect relationship between associations. This also is a problem with the small size and heterogeneous samples of included studies. HRV is responsive to numerous variables (e.g., medications, context, psychological variables) and vulnerable to complex interactions. Available data are limited, and generalizations are not possible to determine consistent conclusions about HRV analysis in the BC population, but HRV seems to be a potential tool in clinical practice.

\subsection{Effects of cancer on HRV}

There are scarce evidences about HRV differences between BC patients/survivors and healthy controls (few studies and multiple confounders). In this present review, three studies investigated BC patients as compared to healthy groups (Bettermann et al., 2001; Tjeerdsma et al., 1999; Vigo et al., 2015). The results showed significantly differences in Tjeerdsma et al. (1999) and Vigo et al. (2015) studies, and no differences in Bettermann et al. (2001) study (see Section 3). Similarly, Caro-Morán et al. (2016) investigated HRV in $22 \mathrm{BC}$ survivors in the first year posttreatment and 22 healthy age- and sex-matched subjects. The results showed differences in time [SDNN, RMSSD (ms), and HRV index] and frequency [HF $\left.\left(\mathrm{ms}^{2}\right)\right]$ domain, which were found lower in BC survivors. The covariates studied (age, educational level, marital status, occupation, smoking habit, alcohol use, menopausal status, heigh, weight, and BMI) showed no influence in HRV analysis. There is a lack of evidences in literature concerning the effect of BC per se on HRV. These studies were developed with patients that had already completed different oncologic treatments, which can influences HRV parameters in addition to other factors (e.g., type of surgery, time since surgery, psychological factors).

Likewise, according to the reviewed studies, the effects of BC stage on HRV remain unclear. Bettermann et al. (2001) was the only study that compared metastatic patients with non-metastatic patients, and HRV was similar. Giese-Davis et al. (2015) observed the association of HRV with survival was maintained in analysis that focused only on women with metastatic disease and excluded women with recurrence disease. This association was little to no effect in predicting survival in women with visceral metastases. Gidron et al. (2014) suggested that higher vagal modulation might protect against the adverse effects of advanced cancer stages. This study compared HRV and tumor markers in colorectal cancer and prostate cancer patients. They observed higher tumor marker levels in patients with advanced cancer stages and low HRV (SDNN $<20 \mathrm{~ms}$ ). Advanced tumor stage patients with high HRV at diagnosis had lower tumor marker levels predicted than had subjects with low HRV in both types of cancers. In this sense, the possibility of neuroimmunomodulatory effects of vagal nerve activity on tumors is highly supported (Gidron et al., 2014).

\subsection{Adverse effects of BC treatments on HRV}

There is a growing prevalence of cancer therapy side effects, notably cardiovascular toxicity (Gulati et al., 2014; Ky et al., 2014), magnified by the lack of ability to identify patients at increased risk for cardiotoxicity, both before and early in therapy (Ky et al., 2014). Given the increased survival rates of patients with BC, and with an increasingly aging population, comorbid illnesses and in particular diseases of cardiovascular system and long-term cardiovascular care are becoming an important clinical problem (Gulati et al., 2014; Zambelli et al., 2011). Potential cardiovascular toxicities linked to anti-cancer agents include QT prolongation and arrhythmias, the induction of myocardial ischaemia and infarction, hypertension or venous and arterial thrombo-embolism, and cardiac dysfunction or heart failure (Eschenhagen et al., 2011). Left ventricular dysfunction is a late marker and becomes evident after significant myocardial damage already has occurred (Lakoski et al., 2015).

As described in Section 1, ANS function is one component involved in the etiology and the clinical course of BC therapyinduced cardiovascular disorders (Scott et al., 2014), and autonomic dysfunctions are associated to increased cardiovascular disease risk in BC patients (Lakoski et al., 2015). Lenneman et al. (2014) showed for the first time in humans that an increase in sympathetic tone via the neuregulin-HER2 pathways might be a key mechanism causing cardiac dysfunction in BC patients treated with transtuzumab or laptanib. Anti-HER2 treatment (e.g., transtuzumab or laptanib) causes an increase in norepinephrine, blood pressure with a corresponding decrease in neuregulin, suggesting that the inhibition of neuregulin-HER2 signalling leads to increased sympathoneural tone (Lenneman et al., 2014).

In this sense, Meinardi et al. (2001) and Tjeerdsma et al. (1999) focused on HRV to analyze autonomic function associated to cardiotoxicity effects of CT in BC patients. The results showed no persistent reduction of HRV after anthracycline CT (Meinardi et al., 2001), and high prevalence of autonomic impairment in BC patients treated with high dose anthracycline CT and RT (Tjeerdsma et al., 1999). However, Meinardi et al. (2001) found HRV reduction 1-year post $\mathrm{CT}$ and the incidence of abnormal cardiac function appears to increase with the length of follow-up after treatment (Carver et al., 2007). Tjeerdsma et al. (1999) included very heterogeneous participants on analysis, average of $29( \pm 27)$ months after CT regiment (range 1-108 months). Anthracycline-associated heart damage is thought to occur largely at the time of exposure, but presentation may occur years later, consequence of the heart being unable, or no longer able to compensate for the initial damage (Eschenhagen et al., 2011).

In the case of cancer therapy-induced cardiotoxicity, both identifying affected patients early and monitoring their response to therapy may have important clinical implications (Gulati et al., 2014). Early identification of subclinical cardiac dysfunction and of patients at higher risk could allow cardioprotective strategies, prevent the interruption or discontinuation of cancer therapy, and reduce early and late cardiovascular and oncological morbidity and mortality (Ky et al., 2014). The current screening methods are lacking an adequate predictive power (Ky et al., 2014; Zambelli et al., 2011). The discovery of new strategies to identify patients at a high risk before significant damage develops for the development of these complications is now a clinical priority (Lakoski et al., 2015; Zambelli et al., 2011). HRV assessment appears to be a potential instrument to cardiovascular impairments detection in BC patients and further investigation are needed. 
Even BC surgery appears to cause autonomic imbalance. Hansen et al. (2013) investigated effects of BC surgery treatment on HRV as circadian variation because of possible cardiovascular complications (Hansen et al., 2013). The results showed BC patients with ANS not fully normalized, decreased HRV, 14 days after lumpectomy (Hansen et al., 2013). Circadian disturbances are demonstrated in the secretion of hormones, the sleep-wake cycle, core body temperature rhythm, autonomic nervous system tone, myocardial ischaemia, and activity rhythm after surgery (Gogenur, 2010). Lower HRV was revealed an atrial fibrillation risk factor in the postoperative period in patients undergoing major pulmonary resection (Ciszewski et al., 2013). The authors suggested that HRV measurement during the perioperative period in lung cancer patients could support recommendation of antiarrhythmic treatment (Ciszewski et al., 2013).

\subsection{Effects of age and BMI on HRV}

The effects of age and BMI should be considered in HRV analysis. Inverse relationship between HRV and age, and BMI are observed in healthy groups (Antelmi et al., 2004; Thayer et al., 2010; Zhao et al., 2015). Decreased influence of parasympathetic drive occurs with increasing age (Antelmi et al., 2004; Thayer et al., 2010; Zhao et al., 2015), and ANS, particularly the sympathetic component, is involved in body weight regulation through energy expenditure modulation. As a result, sympathetic drive could influence body weight. Higher BMI and increased energy expenditures could be modulated through sympathetic nervous system. Additionally, reduction of parasympathetic is related to body size increases, and it may represent a defensive mechanism against fat deposition (Koenig et al., 2014; Molfino et al., 2009).

The age was controlled in Crosswell et al. (2014) (<50 years), Meinardi et al. (2001) (<55 years) and Tjeerdsma et al. (1999) (30-55 years) studies. No studies considered BMI influence on HRV analysis, but Fagundes et al. (2011) excluded patients with $\mathrm{BMI} \geq 40$. According to Crosswell et al. (2014), female BC survivors would have lower HRV (RMSSD and HF) if they were older and had a higher BMI. Vigo et al. (2015) observed BC survivors older and with greater BMI as compared to controls, but these variables were not analyzed to correlate with HRV. A recent study showed similar results. In the Caro-Morán et al. (2016) study, BC survivors were characterized with higher BMI than healthy age- and sexmatched control subjects. However, BMI showed no influence on HRV parameters (Caro-Morán et al., 2016). This characteristic is in accordance to the clinical phenotype of BC survivors proposed by Vigo et al. (2015), which can be due autonomic impairments (i.e., metabolic proxies).

\subsection{Positive effects of supportive interventions}

The randomized trials included in this review showed supportive interventions of relaxation (Minowa and Koitabashi, 2013) and massage (Fernández-Lao et al., 2012) with positive effects on BC patients and survivors through HRV measures. The use of massage therapy was used as a body-centered early intervention in the aftercare program of subgroups of BC survivors with positive attitude toward massage to reduce fatigue, improve cardiovascular autonomic balance, and stabilize mood state (Fernández-Lao et al., 2012). Relaxation practice showed reductions on perioperative anxiety and pain in patients with BC (Minowa and Koitabashi, 2013). The authors suggested relaxation as a simple intervention that patients can practice anytime and anywhere, and it might be very useful for stress management (Minowa and Koitabashi, 2013). Importantly, confounders must be considered. Fernández-Lao et al. (2012) included patients between 25 and 65 years old with an interest in improving their lifestyle and used a single operator pro- cedure. Minowa and Koitabashi (2013) did not control age and type of surgery.

Another example of supportive intervention is physical activity as showed by Niederer et al. (2013). The results indicated moderate aerobic endurance activity improving autonomic cardiac regulation (HRV analysis, frequency domain-TP) and quality of life in cancer patients both during and after acute cancer treatment. This regulation therefore might be considered as an additional benefit of the overall individualized cancer therapy. (Niederer et al., 2013).

\subsection{The methods used to HRV analysis}

Various methods were used to measure HRV indexes values by the included studies (e.g., electrocardiogram, Holter, heart rate monitor, time of recording, software). According to Task Force (1996), two types of recordings should be used whenever possible to standardize physiological and clinical studies: short-term recordings of $5 \mathrm{~min}$ made under physiologically stable conditions processed by frequency domain methods, and nominal 24-h recordings processed by time domain methods. The only standard observed between the studies was short-term recordings in BC survivors and long-term records in $\mathrm{BC}$ patients. There was no standard about the methods used, or about the time or frequency domain.

The most common instrument used to measure HRV was ECG. Only one study used different instrument: a heart rate monitor (Fagundes et al., 2011). In a continuous ECG record, which usually requires a high-quality ECG with a sampling rate above $250 \mathrm{~Hz}$, each QRS complex is detected and the HRV indexes are calculated (Task Force, 1996). A number of ambulatory ECG recorders or Holter monitors that meet these requirements have been developed and are available commercially. They are, however, costly, complex, expensive, and time consuming, and require trained personnel to operate effectively to use out of laboratory, thus making the HRV analysis difficult (Gamelin et al., 2006; Nunan et al., 2009). Fagundes et al. (2011) used a Polar s810 to collect HRV data, a valid instrument with no bias to HRV analysis (Gamelin et al., 2006; Nunan et al., 2009). The Polar S810 is a wireless heart-rate monitoring system capable of recording short-term RR interval data and along with accompanying software allows for an affordable and a user-friendly method to determine HRV outside of the laboratory setting (Nunan et al., 2009).

When HRV methods are employed in an experimental or clinical setting, researchers should ensure that the reliability of measures is high. We can define reliability as the reproducibility of measurements (Portney and Watkins, 2008). In order to obtain reliable HRV data, it is recommended that standardized procedures be used for better assessment of puzzling variables that may affect reliability (Sandercock et al., 2005).

It is shown in the literature that the assessment of the power of the LF band of HRV spectrum obtained from short periods shows high level of reliability with a coefficient of variation of $15 \%$ (Freed et al., 1994). A study from Sinnreich et al. (1998) evaluated HRV parameters in patients under normal or paced breathing. It was seen that measurements of the LF and HF power made 2 months apart had coefficient of variation around $11 \%$. In addition, it was shown that time domain measures had higher reproducibility when assessed 2 months apart because the coefficient of variation was around $6 \%$ for standard deviation of interbeat intervals measures and $7.7 \%$ for RMSSD measures. For both time and frequency domain measures the coefficient of variation was found similar among subjects with normal or paced breathing (Sinnreich et al., 1998).

Despite the low coefficient of variation found by Sinnreich et al. (1998), there are reports showing high variation of values when HRV measures are taken repeatedly over time (Lord et al., 2001; Salo et al., 1999). Therefore, because HRV measures rely very much on data acquisition, the proper choice of sampling equipment 
and maintenance of similar environmental conditions for patients should enhance data reproducibility among measures (Task Force, 1996).

Finally, it is noteworthy to mention statistical considerations for HRV analysis. The methodologies used to quantify HRV in the reviewed articles are quite diverse. All studies have described whether the data was processed for carrying out a parametric analysis, and when necessary, some studies log-transformed HRV indices for proper statistical analysis (See Table 1). Lewis et al. (2012) showed 3 commonly metrics of respiratory sinus arrhythmia highly inter-correlated, but different in terms of statistical features, moderation by respiration, distortion due to nonstationarities, and sensitivity to vagal manipulations. Therefore, the analyses grant that the metrics are not equivalent, and need appropriate transformations and effective detrending procedures (Lewis et al., 2012). Accordingly, we strongly recommend that researchers on the HRV field should verify if data is not violating statistical assumptions for parametric analyses to ensure proper results interpretation regarding time (e.g., RMSSD, SDANN, and SDNN) and frequency (e.g., LF power, HF power, and LF/HF ratio) domain analysis.

\subsection{Directions for future research}

Future studies with long-term follow-up periods, assessment of the influence of different treatments, evaluation of ethnic differences, larger sample sizes, prospective design, homogeneous populations, and detailed analysis on contributing factors, such as preoperative comorbidity and pre-diagnosis exercise data on women, are necessary for a better understanding of the relationship between BC outcomes and HRV parameters. In addition, the use of medications that have an influence on HRV also should be controlled in studies.

\section{Conclusions}

In summary, in this review we showed important studies that aimed to assess HRV, by means of several methodological approaches, in BC patients. The importance of using HRV as a clinical indicator of independent risk factor for evaluating and identifying health impairments involving autonomic changes is promising. The results promise identification of risk patients to cardiovascular events because of autonomic impairments, such as BC patients older and/or with higher BMI. The HRV analysis could be used as a complementary non-invasive tool for the early diagnosis and better prognosis of autonomic dysfunction, and survival in BC patients. There are many potential clinical applications of HRV analysis in BC patients, and the employment of such approaches could lead to lower impairment of autonomic function in this individuals.

\section{Conflicts of interest}

None.

\section{Funding}

None.

\section{Acknowledgement}

None.

\section{References}

Akselrod, S., Gordon, D., Ubel, F.A., Shannon, D.C., Berger, A.C., Cohen, R.J., 1981 Power spectrum analysis of heart rate fluctuation: a quantitative probe of beat-to-beat cardiovascular control. Science 213, 220-222.

Al-Majid, S., McCarthy, D.O., 2001. Cancer-induced fatigue and skeletal muscle wasting: the role of exercise. Biol. Res. Nurs. 2, 186-197.

Antelmi, I., De Paula, R.S., Shinzato, A.R., Peres, C.A., Mansur, A.J., Grupi, C.J., 2004. Influence of age gender, body mass index, and functional capacity on heart rate variability in a cohort of subjects without heart disease. Am. J. Cardiol. 93, $381-385$.

Appel, M.L., Berger, R.D., Saul, J.P., Smith, J.M., Cohen, R.J., 1989. Beat to beat variability in cardiovascular variables: noise or music? J. Am. Coll. Cardiol. 14, 1139-1148.

Badilini, F., Maison-Blanche, P., Coumel, P., 1998. Heart rate variability in passive tilt test: comparative evaluation of autoregressive and FFT spectral analyses. Pacing Clin. Electrophysiol. 21, 1122-1132.

Barron, T.I., Connolly, R.M., Sharp, L., Bennett, K., Visvanathan, K., 2011. Beta blockers and breast cancer mortality: a population based study. J. Clin. Oncol. 29, 2635-2644.

Bettermann, H., Kroz, M., Girke, M., Heckmann, C., 2001. Heart rate dynamics and cardiorespiratory coordination in diabetic and breast cancer patients. Clin. Physiol. 21, 411-420.

Cantarero-Villanueva, I., Fernández-Lao, C., Fernández-De-Las-Peñas, C., Díaz-Rodríguez, L., Sanchez-Cantalejo, E., Arroyo-Morales, M., 2011. Associations among musculoskeletal impairments depression, body image and fatigue in breast cancer survivors within the first year after treatment. Eur. J. Cancer Care (Engl.) 20, 632-639.

Cantarero-Villanueva, I., Fernández-Lao, C., Díaz-Rodríguez, L., Fernández-de-las-Peñas, C., Ruiz, J.R., Arroyo-Morales, M., 2012. The handgrip strength test as a measure of function in breast cancer survivors relationship to cancer-related symptoms and physical and physiologic parameters. Am. J. Phys. Med. Rehabil. 91, 774-782.

Carver, J.R., Shapiro, C.L., Ng, A., Jacobs, L., Schwartz, C., Virgo, K.S., Vaughn, D.J., 2007. American Society of Clinical Oncology clinical evidence review on the ongoing care of adult cancer survivors: cardiac and pulmonary late effects. J. Clin. Oncol. 25, 3991-4008.

Caro-Morán, E., Fernández-Lao, C., Galiano-Castillo, N., Cantarero-Villanueva, I., Arroyo-Morales, M., Díaz-Rodríguez, L., 2016. Heart rate variability in breast cancer survivors after the first year of treatments: a case-controlled study. Biol. Res. Nurs. 18, 43-49.

Cerutti, C., Gustin, M.P., Paultre, C.Z., Lo, M., Julien, C., Vincent, M., Sassard, J., 1991. Autonomic nervous system and cardiovascular variability in rats: a spectral analysis approach. Am. J. Physiol. 261, H1292-1299.

Chiang, J.K., Kuo, T.B., Fu, C.H., Koo, M., 2013. Predicting 7-day survival using heart rate variability in hospice patients with non-lung cancers. PLoS One 8, e69482.

Ciszewski, P., Tyczka, J., Nadolski, J., Roszak, M., Dyszkiewicz, W., 2013. Lower preoperative fluctuation of heart rate variability is an independent risk factor for postoperative atrial fibrillation in patients undergoing major pulmonary resection. Interact. Cardiovasc. Thorac. Surg. 17, 680-686.

Cole, S.W., Sood, A.K., 2012. Molecular pathways: beta-adrenergic signaling in cancer. Clin. Cancer Res. 18, 1201-1206.

Crosswell, A.D., Lockwood, K.G., Ganz, P.A., Bower, J.E., 2014. Low heart rate variability and cancer-related fatigue in breast cancer survivors. Psychoneuroendocrinology 45, 58-66.

De Couck, M., Mravec, B., Gidron, Y., 2012. You may need the vagus nerve to understand pathophysiology and to treat diseases. Clin. Sci. 122, 323-328.

Durosier, L.D., Green, G., Batkin, I., Seely, A.J., Ross, M.G., Richardson, B.S., Frasch, M.G., 2014. Sampling rate of heart rate variability impacts the ability to detect acidemia in ovine fetuses near-term. Front. Pediatr. 2, 38.

Ellis, R.J., Zhu, B., Koenig, J., Thayer, J.F., Wang, Y., 2015. A careful look at ECG sampling frequency and R-peak interpolation on short-term measures of heart rate variability. Physiol. Meas. 36, 1827-1852.

Erin, N., Barkan, G.A., Harms, J.F., Clawson, G.A., 2008. Vagotomy enhances experimental metastases of 4 THMpc breast cancer cells and alters substance $P$ level. Regul. Pept. 151, 35-42.

Eschenhagen, T., Force, T., Ewer, M.S., de Keulenaer, G.W., Suter, T.M., Anker, S.D., Avkiran, M., de Azambuja, E., Balligand, J.L., Brutsaert, D.L., Condorelli, G., Hansen, A., Heymans, S., Hill, J.A., Hirsch, E., Hilfiker-Kleiner, D., Janssens, S., de Jong, S., Neubauer, G., Pieske, B., Ponikowski, P., Pirmohamed, M., Rauchhaus, M., Sawyer, D., Sugden, P.H., Wojta, J., Zannad, F., Shah, A.M., 2011. Cardiovascular side effects of cancer therapies: a position statement from the heart failure association of the European Society of Cardiology. Eur. J. Heart Fail. 13, 1-10

Fadul, N., Strasser, F., Palmer, J.L., Yusuf, S.W., Guo, Y., Li, Z., Allo, J., Bruera, E., 2010 The association between autonomic dysfunction and survival in male patients with advanced cancer: a preliminary report. J. Pain Symptom Manag. 39, $283-290$

Fagundes, C.P., Murray, D.M., Hwang, B.S., Gouin, J.P., Thayer, J.F., Sollers J.J3rd. Shapiro, C.L., Malarkey, W.B., Kiecolt-Glaser, J.K., 2011. Sympathetic and parasympathetic activity in cancer-related fatigue: more evidence for a physiological substrate in cancer survivors. Psychoneuroendocrinology 36 1137-1147.

Ferlay, J., Soerjomataram, I., Dikshit, R., Eser, S., Mathers, C., Rebelo, M., Parkin, D.M., Forman, D., Bray, F., 2015. Cancer incidence and mortality worldwide: sources methods major patterns in GLOBOCAN 2012. Int. J. Cancer 136, E359-E386. 
Fernández-Lao, C., Cantarero-Villanueva, I., Díaz-Rodriguez, L., Cuesta-Vargas, A.L. Fernández-Delas-Peñas, C., Arroyo-Morales, M., 2012. Attitudes towards massage modify effects of manual therapy in breast cancer survivors: a randomised clinical trial with crossover design. Eur. J. Cancer Care (Engl.) 21, 233-241.

Freed, L.A., Stein, K.M., Gordon, M., Urban, M., Kligfield, P., 1994. Reproducibility of power spectral measures of heart rate variability obtained from short-term sampling periods. Am. J. Cardiol. 74, 972-973.

Gamelin, F.X., Berthoin, S.E.R.G., Bosquet, L., 2006. Validity of the polar S810 heart rate monitor to measure RR intervals at rest. Med. Sci. Sports Exerc. 38, 887-893.

Gidron, Y., Perry, H., Glennie, M., 2005. Does the vagus nerve inform the brain about preclinical tumours and modulate them? Lancet Oncol. 6, 245-248.

Gidron, Y., De Couck, M., De Greve, J., 2014. If you have an active vagus nerve, cancer stage may no longer be important. J. Biol. Regul. Homeost. Agents 28 , 195-201.

Giese-Davis, J., Wilhelm, F.H., Conrad, A., Abercrombie, H.C., Sephton, S., Yutsis, M., Neri, E., Taylor, C.B., Kraemer, H.C., Spiegel, D., 2006. Depression and stress reactivity in metastatic breast cancer. Psychosom. Med. 68, 675-683.

Giese-Davis, J., Wilhelm, F.H., Tamagawa, R., Palesh, O., Neri, E., Taylor, C.B., Kraemer, H.C., Spiegel, D., 2015. Higher vagal activity as related to survival in patients with advanced breast cancer: an analysis of autonomic dysregulation. Psychosom. Med. 77, 346-355.

Gogenur, I., 2010. Postoperative circadian disturbances. Dan Med. Bull. 57, 1-20.

GRADE Working Group, 2004. Grading quality of evidence and strength of recommendations. BMJ 328, 1490-1494.

Gulati, G., Zhang, K.W., Scherrer-Crosbie, M., Ky, B., 2014. Cancer and cardiovascular disease: the use of novel echocardiography measures to predict subsequent cardiotoxicity in breast cancer treated with anthracyclines and trastuzumab. Curr. Heart Fail. Rep. 11, 366-373.

Hansen, M.V., Rosenberg, J., Gögenur, I., 2013. Lack of circadian variation and reduction of heart rate variability in women with breast cancer undergoing lumpectomy: a descriptive study. Breast Cancer Res. Treat. 140, 317-322.

Hejjel, L., Roth, E., 2004. What is the adequate sampling interval of the ECG signal for heart rate variability analysis in the time domain? Physiol. Meas. 25, 1405-1411.

Højgaard, M.V., Holstein-Rathlou, N.H., Agner, E., Kanters, J.K., 1998. Dynamics of spectral components of heart rate variability during changes in autonomic balance. Am. J. Physiol. 275, H213-H219.

Karvinen, K.H., Murray, N.P., Arastu, H., Allison, R.R., 2013. Stress reactivity health behaviors, and compliance to medical care in breast cancer survivors. Oncol. Nurs. Forum 40, 149-156.

Kim, H., Kim, J.A., Choi, Y.S., Kim, S.H., Lee, J.Y., Kim, Y.E., 2010. Heart rate variability and length of survival in hospice cancer patients. J. Korean Med. Sci. 25 1140-1145.

Koenig, J., Jarczok, M.N., Warth, M., Ellis, R.J., Bach, C., Hillecke, T.K., Thayer, J.F., 2014. Body mass index is related to autonomic nervous system activity as measured by heart rate variability-a replication using short term measurements. J. Nutr. Health Aging 18, 300-302.

Ky, B., Putt, M., Sawaya, H., French, B., Januzzi J.L.Jr. Sebag, I.A., Plana, J.C., Cohen, V. Banchs, J., Carver, J.R., Wiegers, S.E., Martin, R.P., Picard, M.H., Gerszten, R.E., Halpern, E.F., Passeri, J., Kuter, I., Scherrer-Crosbie, M., 2014. Early increases in multiple biomarkers predict subsequent cardiotoxicity in patients with breast cancer treated with doxorubicin, taxanes, and trastuzumab. J. Am. Coll. Cardiol 63, 809-816.

Lakoski, S.G., Jones, L.W., Krone, R.J., Stein, P.K., Scott, J.M., 2015. Autonomic dysfunction in early breast cancer: incidence clinical importance, and underlying mechanisms. Am. Heart J. 70, 231-241.

Lenneman, C.G., Abdallah, W.M., Smith, H.M., Abramson, V., Mayer, I.A., Silverstein, C., Means-Powell, J., Paranjape, S.Y., Lenihan, D., Sawyer, D.B., Raj, S.R., 2014 Sympathetic nervous system alterations with HER2+ antagonism: an early marker of cardiac dysfunction with breast cancer treatment? Ecancermedicalscience 8, 1-9.

Lewis, G.F., Furman, S.A., McCool, M.F., Porges, S.W., 2012. Statistical strategies to quantify respiratory sinus arrhythmia: are commonly used metrics equivalent? Biol. Psychol. 89, 349-364.

Liberati, A., Altman, D.G., Tetzlaff, J., Mulrow, C., Gøtzsche, P.C., Ioannids, J.P.A., Clarke, M., Devereaux, P.J., Kleijnen, J., Moher, D., 2009. The PRISMA statement for reporting systematic reviews and meta-analyses of studies that evaluate healthcare interventions: explanation and elaboration. BMJ 339 (July (21)), b2700.

Lin, S.C., Chen, M.F., 2010. Increased yin-deficient symptoms and aggravated autonomic nervous system function in patients with metastatic cancer. J. Altern. Complement. Med. 16, 1059-1063.

Lombardi, F., Stein, P.K., 2011. Origin of heart rate variability and turbulence: an appraisal of autonomic modulation of cardiovascular function. Front. Physiol. $2,1-7$.

Lord, S.W., Senior, R.R., Das, M., Whittam, A.M., Murray, A., McComb, J.M., 2001 Low-frequency heart rate variability: reproducibility in cardiac transplant recipients and normal subjects. Clin. Sci. 100, 43-46.

Malliani, A., Pagani, M., Lombardi, F., Cerutti, S., 1991. Cardiovascular neura regulation explored in the frequency domain. Circulation 84, 482-492.

Malliani, A., Montano, N., Pagani, M., 1997. Physiological background of heart rate variability. Card. Electrophysiol. Rev. 3, 343-346.

Meinardi, M.T., Van Veldhuisen, D.J., Gietema, J.A., Dolsma, W.V., Boomsma, F., Van Den Berg, M.P., Van Der Graaf, W.T.A., 2001. Prospective evaluation of early cardiac damage induced by epirubicin-containing adjuvant chemotherapy and locoregional radiotherapy in breast cancer patients. J. Clin. Oncol. 19, 2746-2753.

Melhem-Bertrandt, A., Chavez-Macgregor, M., Lei, X., Brown, E.N., Lee, R.T. Meric-Bernstam, F., Sood, A.K., Conzen, S.D., Hortobagyi, G.N., Gonzalez-Angulo, A.M., 2011. Beta-blocker use is associated with improved relapse-free survival in patients with triple-negative breast cancer. J. Clin. Oncol. 29, 2645-2652.

Minowa, C., Koitabashi, K., 2013. Effects of autogenic training on perioperative anxiety and pain in breast cancer patients. Kika Kanto Igaku. 63, 1-11.

Moher, D., Liberati, A., Tetzlaff, J., Altman, D.G., 2009. Preferred reporting items for systematic reviews and meta-analyses: the PRISMA statement. Ann. Intern. Med. 151, 264-269.

Molfino, A., Fiorentini, A., Tubani, L., Martuscelli, M., Fanelli, F.R., Laviano, A., 2009. Body mass index is related to autonomic nervous system activity as measured by heart rate variability. Eur. J. Clin. Nutr. 63, 1263-1265.

Mollakazemi, M.J., Atyabi, S.A., Ghaffari, A., 2015. Heart beat detection using multimodal data coupling method. Physiol. Meas. 36, 1729-1742.

Niederer, D., Vogt, L., Thiel, C., Schmidt, K., Bernhörster, M., Lungwitz, A., Jäger, E. Banzer, W., 2013. Exercise effects on HRV in cancer patients. Int. J. Sports Med. $34,68-73$.

Nunan, D., Donovan, G., Jakovljevic, D., Hodges, L., Sandercock, G., Brodie, D., 2009. Validity and reliability of short-term heart-rate variability from the Polar S810. Med. Sci. Sports Exerc. 41, 243-250.

Ondicova, K., Mravec, B., 2010. Role of nervous system in cancer aetiopathogenesis. Lancet Oncol. 11, 596-601.

Pomeranz, B., Macaulay, R.J., Caudill, M.A., Kutz, I., Adam, D., Gordon, D., Kilborn, K.M., Barger, A.C., Shannon, D.C., Cohen, R.J., 1985. Assessment of autonomic function in humans by heart rate spectral analysis. Am. J. Physiol. 248, H151-153.

Portney, L., Watkins, M.P., 2008. Foundations of Clinical Research: Applications to Practice, 3rd edition. Prentice Hall Upper Saddle River, N.J.

Rimoldi, O., Pierini, S., Ferrari, A., Cerutti, S., Pagani, M., Malliani, A., 1990. Analysis of short-term oscillations of R-R and arterial pressure in conscious dogs. Am. J. Physiol. 258, H967-976.

Salo, T.M., Voipio-Pulkki, L.M., Jalonen, J.O., Helenius, H., Viikari, J.S., Kantola, I., 1999. Reproducibility of abnormal heart rate variability indices: the case of hypertensive sleep apnoea syndrome. Clin. Physiol. 19, 258-268.

Sandercock, G.R.H., Bromley, P.D., Brodie, D.A., 2005. The reliability of short-term measurements of heart rate variability. Int. J. Cardiol. 103, 238-247.

Scott, J.M., Jones, L.W., Hornsby, W.E., Koelwyn, G.J., Khouri, M.G., Joy, A.A., Douglas, P.S., Lakoski, S.G., 2014. Cancer therapy-induced autonomic dysfunction in early breast cancer: Implications for aerobic exercise training. Int. J. Cardiol. 171, e50-e51.

Shaffer, F., McCraty, R., Zerr, C.L., 2014. A healthy heart is not a metronome: an integrative review of the heart's anatomy and heart rate variability. Front. Psychol. 5, 1040

Sinnreich, R., Kark, J.D., Friedlander, Y., Sapoznikov, D., Luria, M.H., 1998. Five minute recordings of heart rate variability for population studies: repeatability and age-sex characteristics. Heart 80, 156-162.

Task Force, 1996. Heart rate variability: standards of measurement, physiological interpretation and clinical use. Task force of the European Society of Cardiology and the North American Society of Pacing and Electrophysiology. Circulation 93, 1043-1065.

Thaker, P.H., Han, L.Y., Kamat, A.A., Arevalo, J.M., Takahashi, R., Lu, C., Jennings, N.B., Armaiz-Pena, G., Bankson, J.A., Ravoori, M., Merritt, W.M., Lin, Y.G., Mangala, L.S., Kim, T.J., Coleman, R.L., Landen, C.N., Li, Y., Felix, E., Sanguino, A.M., Newman, R.A., Lloyd, M., Gershenson, D.M., Kundra, V., Lopez-Berestein, G. Lutgendorf, S.K., Cole, S.W., Sood, A.K., 2006. Chronic stress promotes tumo growth and angiogenesis in a mouse model of ovarian carcinoma. Nat. Med. 12, 939-944.

Thayer, J.F., Yamamoto, S.S., Brosschot, J.F., 2010. The relationship of autonomic imbalance: heart rate variability and cardiovascular disease risk factors. Int. J. Cardiol. 141, 122-131.

Thayer, J.F., Åhs, F., Fredrikson, M., Sollers J.J3rd. Wager, T.D., 2012. A meta-analysis of heart rate variability and neuroimaging studies: Implications for heart rate variability as a marker of stress and health. Neurosci. Biobehav. Rev. 36, 747-756.

Tjeerdsma, G., Meinardi, M.T., van Der Graaf, W.T., van Den Berg, M.P., Mulder, N.H., Crijns, H.J., de Vries, E.G., van Veldhuisen, D.J., 1999. Early detection of anthracycline induced cardiotoxicity in asymptomatic patients with normal left ventricular systolic function: autonomic versus echocardiographic variables. Heart 81, 419-423.

Vanderlei, L.C.M., Pastre, C.M., Hoshi, R.A., de Carvalho, T.D., de Godoy, M.F., 2009 Noções básicas de variabilidade da frequência cardíaca e sua aplicabilidade clínica. Rev. Bras. Circ. Cardiovasc. 24, 205-217.

Vigo, C., Gatzemeier, W., Sala, R., Malacarne, M., Santoro, A., Pagani, M., Lucini, D. 2015. Evidence of altered autonomic cardiac regulation in breast cancer survivors. J. Cancer Surviv, 9, 699-706.

Wang, Y.M., Wu, H.T., Huang, E.Y., Kou, Y.R., Hseu, S.S., 2013. Heart rate variability is associated with survival in patients with brain metastasis: a preliminary report. Biomed. Res. Int. 2013, 1-6.

Winters-Stone, K.M., Bennett, J.A., Nail, L., Schwartz, A., 2008. Strength physical activity, and age predict fatigue in older breast cancer survivors. Oncol. Nurs. Forum 35, 815-821.

Zambelli, A., Della Porta, M.G., Eleuteri, E., De Giuli, L., Catalano, O., Tondini, C., Riccardi, A., 2011. Predicting and preventing cardiotoxicity in the era of breast 
cancer targeted therapies. Novel molecular tools for clinical issues. Breast 20 , $176-183$.

Zaza, A., Lombardi, F., 2001. Autonomic indexes based on the analysis of heart rate variability: a view from the sinus node. Cardiovasc. Res. 50, 434-442.
Zhao, R., Li, D., Zuo, P., Bai, R., Zhou, Q., Fan, J., Li, C., Lin, W., Yang, X., 2015.

Influences of age gender, and circadian rhythm on deceleration capacity in subjects without evident heart diseases. Ann. Noninvasive Electrocardiol. 20, 158-166. 